\title{
Effect of Cysteic Acid Position on the Negative Ion Fragmentation of Proteolytic Derived Peptides
}

\author{
Brad J. Williams, Kevin L. Kmiec, William K. Russell, David H. Russell \\ Department of Chemistry, Texas A\&M University, College Station, TX, 77843, USA
}

\begin{abstract}
A study on the effect of cysteic acid position on the types of fragment ions formed by collisioninduced dissociation (CID) of $\left[\mathrm{M}-\mathrm{H}^{-}\right.$ions is presented. Of particular note is the observation of $\mathrm{d}$-type fragment ions for peptides that contain an $\mathrm{N}$-terminal cysteic acid (fixed negative charge) and cleavable amino acid side chains possessing a $\beta$-y carbon-carbon bond. For example, the CID mass spectrum of oxidized cys-kemptide ( $\mathrm{C}_{\text {ox }}$ LRRASLG) $\left[\mathrm{M}-\mathrm{H}+\mathrm{O}_{3}\right]^{-}$ions contains abundant series of d-type fragment ions, and similar results are observed for oxidized cysteinecontaining ribonuclease A proteolytic peptides. The $d_{i}$ fragment ions are assumed to arise by a charge-remote and/or charge-assisted fragmentation mechanism, which both occur at high collision energies and involve consecutive reactions (i.e., the formation of $a_{i}$ ions followed by the elimination of the side chain to form $d_{i}$ ions).
\end{abstract}

Key words: On-target performic acid oxidation, Negative ion tandem mass spectrometry, Cysteic-acid-containing peptides, $d$-type fragment ions, Ribonuclease A, MALDI-MS

\section{Introduction}

$\mathrm{T}$ he vast majority of proteomics studies utilize positive ion data from single and multiple stages of mass spectrometry (MS) for protein and peptide identification. However, negative ion MS provides a specific utility for the detection and identification of peptide/protein post-translational modifications (e.g., glycosylation, sulfation, and phosphorylation) [1, 2]. The fragment ion spectrum of peptide $[\mathrm{M}-\mathrm{H}]^{-}$ions provides information not commonly afforded by positive ion tandem mass spectrometry [2, 3]. For example, tandem MS precursor ion scanning techniques provide selective detection of phosphopeptides from a complex mixture owing to the diagnostic neutral loss of $m / z 79\left(\mathrm{PO}_{3}\right)$ or $m / z 97\left(\mathrm{H}_{2} \mathrm{PO}_{4}\right)$ from

Electronic supplementary material The online version of this article (doi:10.1007/s13361-010-0009-4) contains supplementary material, which is available to authorized users.

Correspondence to: David H. Russell; e-mail: russell@mail.chem.tamu.edu the parent $[\mathrm{M}-\mathrm{H}]^{-}$ion in the negative ion mass spectrum [4-7]. In addition, several side chain losses from Asp, Gln, Ser, Thr, and Cys are frequently observed using either positive or negative ion tandem MS, and such losses have considerable utility. For example, side chain loss can be used to differentiate glutamine and lysine, two near-isobaric $(\Delta \mathrm{m}=36 \mathrm{mDa})$ amino acid residues $[3,8]$. In addition, the detection of the various states of cysteine oxidation-i.e., disulfide bonds $(-\mathrm{S}-\mathrm{S}-)$, sulfenic $(-\mathrm{SOH})$, sulfinic $\left(-\mathrm{SO}_{2} \mathrm{H}\right)$ or sulfonic $\left(-\mathrm{SO}_{3} \mathrm{H}\right)$ acidsis becoming increasingly important in many biological processes, including oxidative stress [9-12]. Sulfonic acid is the final oxidation product of many such processes, and negative ion MS has proven effective for the detection of $[\mathrm{M}-\mathrm{H}]^{-}$ions from cysteic-acid-containing peptides [13-15]. To date, a limited number of studies on negative ion fragmentation of cysteic-acid-containing peptides have been reported [14].

Cysteic-acid-containing peptide ions are known to yield abundant fragment ions involving the loss of the cysteic acid side chain $[16,17]$. For example, Gaskell and coworkers have reported d-type fragment ions for $[\mathrm{M}+2 \mathrm{H}]^{2+}$ cysteicacid-containing peptide ions for oxidized RLAIFSC $\mathrm{Ox}_{\mathrm{Ox}} \mathrm{FR}$ 
[16]. Specifically, a $d_{7}$ (partial side-chain loss of $-\mathrm{SO}_{3} \mathrm{H}$ ) fragment ion is observed in the fragment ion mass spectrum, whereas an abundant $d_{3}$ fragment ion is observed for $\mathrm{RLC}_{\mathrm{ox}} \mathrm{IFSAFR}$. They suggest that the cysteic acid is involved in the d-type fragment ion formation mechanism through the interaction with the N-terminal arginine side chain. In earlier work they investigated the positive ion fragmentation of the N-terminal cysteic-acid-containing peptide ( $\left.\mathrm{C}_{\mathrm{ox}} \mathrm{GQPLQNK}\right)$ [18]. The positive ion tandem mass spectrum is dominated by y-type fragment ion series owing to charge localization at the C-terminal lysine. They conclude that the cysteic acid promotes interaction with the lysine residue at the $\mathrm{C}$-terminus and allows a "mobile proton" to move freely along the peptide backbone $[16,17$, 19].

Here we investigate the effect of cysteic acid position on the fragmentation of $[\mathrm{M}-\mathrm{H}]^{-}$ions of model peptides and ribonuclease A (RNase A) proteolytic derived peptides. For example, we observe a position dependence of the cysteic acid on the side-chain fragment ion preference; i.e., distinct series of d-type fragment ions are observed for $\mathrm{N}$-terminal cysteic-acid-containing peptides, whereas $\mathrm{v}$ - and w-type fragment ions are observed for C-terminal cysteic-acidcontaining peptides. The formation of d-type fragment ions from N-terminal cysteic-acid-containing model peptides was investigated using native Cys-kemptide (CLRRASLG) and oxidized Cys-kemptide ( $\mathrm{C}_{\mathrm{ox}}$ LRRASLG). The generality of these observations was probed using RNase A proteolytic peptides with the cysteic acid at the N-terminus, near the peptide center, and toward the $\mathrm{C}$-terminus.

\section{Experimental}

\section{Chemicals}

All chemicals were purchased from Sigma-Aldrich (St. Louis, MO, USA) unless otherwise noted. Hydrogen peroxide $(35 \% \mathrm{w} / \mathrm{w})$ and formic acid $(99 \% \mathrm{w} / \mathrm{w})$ were purchased from Acros Organics (Morris Plains, NJ, USA). HPLC-grade acetone and methanol $\left(\mathrm{CH}_{3} \mathrm{OH}\right)$ were purchased from EMD Chemicals Inc. (Gibbstown, NJ, USA). All experiments were performed with $18-\mathrm{M} \Omega$ water $\left(\mathrm{ddH}_{2} \mathrm{O}\right)$ purified using a water purification unit (Barnstead International, Dubuque, IA, USA).

\section{Sample Preparation for MALDI-MS}

A stock solution of Cys-kemptide (CLRRASLG) was prepared at $10 \mu \mathrm{M}$ in $10 \mathrm{mM}$ formic acid. The peptide solution was mixed $1: 1$ with $\mathrm{CH}_{3} \mathrm{OH}$ and $1 \mu \mathrm{L}$ was spotted as an overlayer onto pre-spotted $\alpha$-cyano-4-hydroxycinnamic acid (CHCA) matrix. CHCA was prepared at $5 \mathrm{mg}$ $\mathrm{mL}^{-1}$ in a $2: 3 \mathrm{ddH}_{2} \mathrm{O}: \mathrm{CH}_{3} \mathrm{OH}$ solution containing $10 \mathrm{mM}$ $\mathrm{NH}_{4} \mathrm{H}_{2} \mathrm{PO}_{4}$, and $1 \mu \mathrm{L}$ was pre-spotted as the underlayer [20]. This cysteine-containing peptide was oxidized using the on-target oxidation procedures described below.

\section{Ribonuclease A Proteolytic Digestion}

Dual protease digestion (trypsin followed by chymotrypsin) of RNase A was performed using previously described methods [15, 21]. Briefly, RNase A was dissolved at $1 \mathrm{mg}$ $\mathrm{mL}^{-1}$ in a $25 \mathrm{mM}$ ammonium acetate buffer adjusted to pH 6.0 with $10 \mathrm{mM}$ formic acid. RNase A was digested with and without chemical reduction of the disulfide bonds. For the nonreduced digest, RNase A was initially digested with trypsin (1:50 enzyme:protein ratio) for $4 \mathrm{~h}$ at $37^{\circ} \mathrm{C}$ followed by chymotrypsin addition (1:50 enzyme:protein ratio) and incubation for an additional $4 \mathrm{~h}$. For the reduced RNase A digest, the sample solution was subjected to tris(2-carboxyethyl)-phosphine (TCEP) reduction ( $2 \mu \mathrm{L}$ of $50 \mathrm{mM}$ TCEP prepared in $\mathrm{ddH}_{2} \mathrm{O}$ ) by incubating at $60{ }^{\circ} \mathrm{C}$ for $60 \mathrm{~min}$. Following TCEP reduction, the protein was digested with trypsin followed by chymotrypsin using the same procedure as the nonreduced digest. Following proteolytic digestion, the sample was subjected to cleanup using a $10 \mu \mathrm{L} \mathrm{C}_{18}$ resin pipette tip. The RNase A proteolytic digest was eluted with a 60:40 $\mathrm{CH}_{3} \mathrm{CN}: \mathrm{ddH}_{2} \mathrm{O}$ solution containing $0.1 \%$ formic acid, and $1 \mu \mathrm{L}$ was spotted as the overlayer onto CHCA matrix.

\section{On-Target Performic Acid Oxidation}

On-target performic acid oxidation was performed as described previously [15]. Briefly, $40 \mu \mathrm{L}$ of a 1:1 mixture of acetone: performic acid was placed directly on the MALDI target in a region that does not contain sample. The MALDI target was then covered in a plastic petri dish and allowed to react at room temperature $\left(+24{ }^{\circ} \mathrm{C}\right)$ for $10-60 \mathrm{~min}$. Following on-target performic acid oxidation, the MALDI plate was then subjected to mass spectrometric analysis without sample cleanup.

\section{Mass Spectrometry}

All electrospray ionization (ESI)-MS and MS/MS experiments were performed on an LCQ-Deca (Thermo Finnigan, Waltham, MA, USA) mass spectrometer equipped with a quadrupole ion trap for MS/MS and $\mathrm{MS}^{\mathrm{n}}$ experiments. The MS/MS and $\mathrm{MS}^{\mathrm{n}}$ experiments were performed in the negative ionization mode using optimized collision energies (ca. 35-50 V) for [M-H] precursor ions. The MALDI-MS experiments were performed using a model 4700 proteomics analyzer, MALDI-TOF/TOF system (Applied Biosystems, Framingham, MA, USA). The MALDI-MS data were acquired using the reflectron detector in both positive and negative ion modes using 1200 laser shots with external calibration using bradykinin (2-9) (PPGFSPFR) and ACTH (18-39) (RPVKVYPNGAENESAEAFPLEF). Positive and negative ion collision-induced dissociation (CID) tandem MS spectra were acquired using 10-20\% greater laser power than the MS spectra acquisition. Two collision gas parameters were used for the $1 \mathrm{kV}$ CID experiments: (i) with atmosphere (ambient air) used as the collision gas, and (ii) without collision gas. The peptide fragmentation nomenclature developed by Roepstorff [22] and modified by Biemann [8] was 
used to describe the side-chain loss fragment ions observed in the negative ion tandem mass spectrum. In regards to the negative ion peptide fragmentation nomenclature developed by Bowie and coworkers, several different side-chain losses are observed in the negative ion tandem mass spectrum of $[\mathrm{M}-\mathrm{H}]^{-}$ peptide ions $[2,3,23]$; however, nomenclature to describe the site of bond cleavage and the type (partial or full) of side-chain loss has not yet been clearly defined. Hence, we chose to use positive ion peptide fragmentation nomenclature to describe the side-chain loss fragment ions.

\section{Results and Discussion}

Figure 1 contains the negative ion fragmentation data for both native (CLRRASLG) and oxidized Cys-kemptide $\left(\mathrm{C}_{\text {ox }}\right.$ LRRASLG). Native cys-kemptide $[\mathrm{M}-\mathrm{H}]^{-}$ions yield a near-complete series of y-type fragment ions and an abundant $\mathrm{c}_{5}$ fragment ion. We interpret the abundant series of $\mathrm{y}$-type fragment ions as evidence that the charge resides primarily on the C-terminus; i.e., the deprotonated carboxylate group from glycine. It is also interesting to note that several characteristic fragment ions involving the side chains of arginine, cysteine and serine amino acids are also observed: $\left[\mathrm{M}-\mathrm{CH}_{2} \mathrm{~N}_{2}\right]^{-}$from $\mathrm{Arg},\left[\mathrm{M}-\mathrm{H}_{2} \mathrm{~S}\right]^{-}$from Cys, and $\left[\mathrm{M}-\mathrm{CH}_{2} \mathrm{O}\right]^{-}$from Ser. Side-chain losses for serine- and cysteine-containing fragment ions are also observed, specifically $\left[\mathrm{y}_{4}-\mathrm{CH}_{2} \mathrm{O}\right],\left[\mathrm{y}_{5}-\mathrm{CH}_{2} \mathrm{O}\right]$, and $\left[\mathrm{c}_{5}-\mathrm{H}_{2} \mathrm{~S}\right]$ fragment ions (Figure 1a).

The fragment ion spectrum of $\mathrm{C}_{\mathrm{ox}}$ LRRASLG $[\mathrm{M}-\mathrm{H}+$ $\left.\mathrm{O}_{3}\right]^{-}$ions acquired without CID collision gas contains abundant N-terminal fragment ions (Figure 1b), as well as fragment ions formed by neutral losses from arginine ([M $\left.\left.\mathrm{CH}_{2} \mathrm{~N}_{2}\right]^{-}\right)$and cysteic acid $\left(\left[\mathrm{M}-\mathrm{H}_{2} \mathrm{SO}_{3}\right]^{-}\right)$side chains. Similar neutral losses of $\mathrm{H}_{2} \mathrm{SO}_{3}$ from precursor and fragment
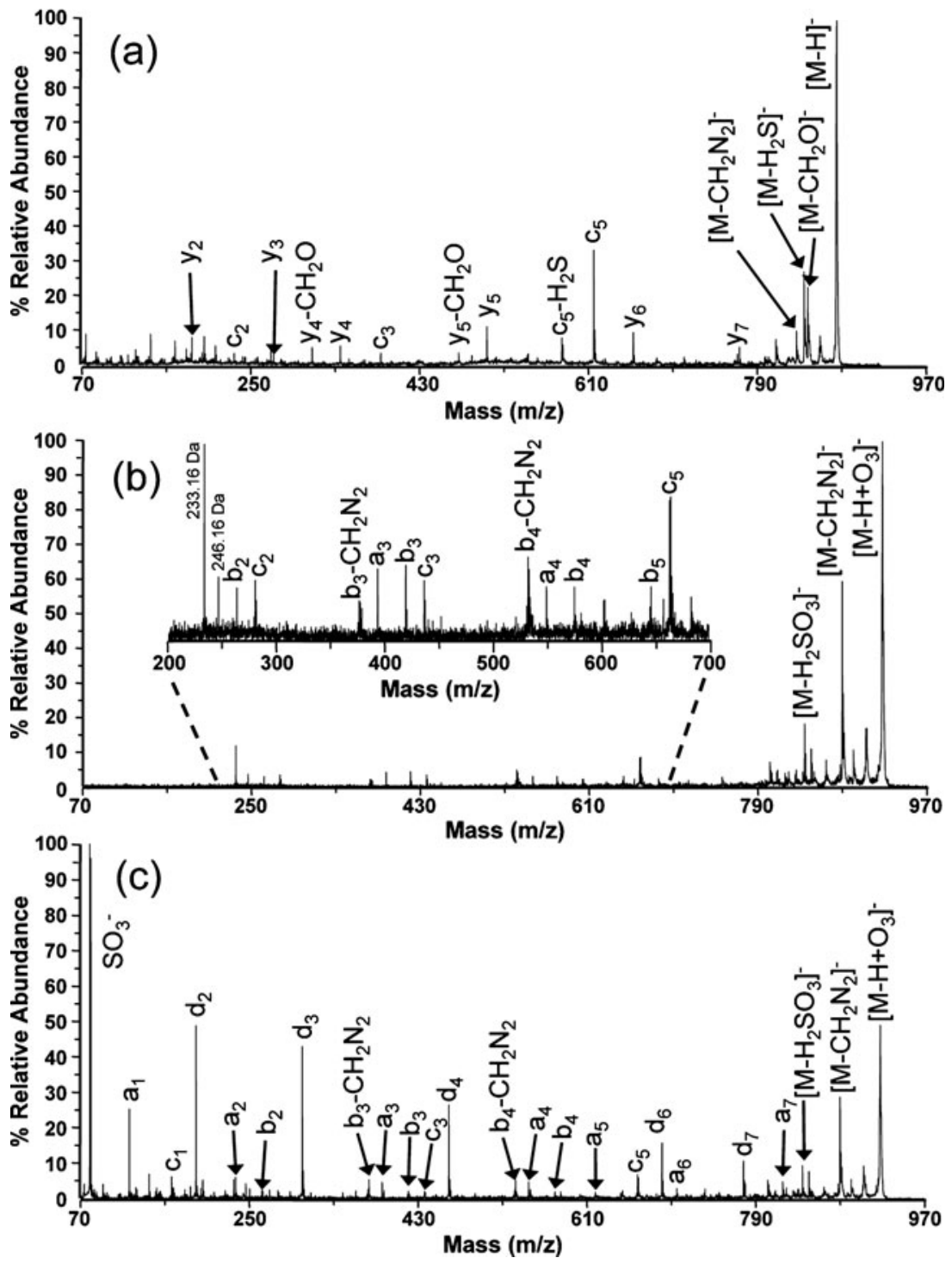

Figure 1. (a) Negative ion tandem mass spectrum of native Cys-kemptide (CLRRASLG) [M - H] $]^{-}$ions fragmented with CID collision gas (atmosphere). Oxidized Cys-kemptide ( $\mathrm{C}_{\mathrm{ox}}$ LRRASLG) $\left[\mathrm{M}-\mathrm{H}+\mathrm{O}_{3}\right]^{-}$ions fragmented without CID collision gas (b) and with CID collision gas (c). Inset figure: expanded view of mass range $\mathrm{m} / \mathrm{z} 200-700$ for (b) 
ions have been reported for positive ion fragmentations of cysteic-acid-containing peptides [17]. It is also important to note that the $\mathrm{c}_{5}$ fragment ion is also observed in the spectrum shown in Figure $1 \mathrm{~b}$. Thus, the $\mathrm{c}_{5}$ fragment ion (cleavage of the $\mathrm{N}-\mathrm{C}^{\alpha}$ bond between alanine and serine) is readily formed under low-energy collision conditions. Abundant series of $c_{i}$ fragment ions are also observed in post-source decay fragment ion spectra of MALDI-formed $[\mathrm{M}-\mathrm{H}]^{-}$peptide ions [24].

The fragment ion spectrum of oxidized Cys-kemptide obtained with CID collision gas (Figure 1c) is very different from that shown in Figures 1a and b. Although the majority of the fragment ions are $\mathrm{N}$-terminal, the most abundant ion signals are d-type fragment ions. Note also that lowabundance a- and b-type fragment ions are observed in Figure 1c, which suggests that the formation of a- or b-type ions could precede the formation of d-type fragment ions (see below). We propose that the $\mathrm{d}_{i}$ fragment ions are formed by a-type backbone cleavage and subsequent side-chain loss through the cleavage of the $\beta-\gamma$ carbon-carbon bond. This idea is consistent with the fact that a $\mathrm{d}_{5}$ fragment ion is not observed because the alanine side chain lacks a cleavable $\beta-\gamma$ carbon-carbon bond. It is also important to note that these side-chain loss fragment ions are not observed in the fragment ion spectrum without CID collision gas, which suggests that the formation of $\mathrm{d}_{i}$ fragment ions is a relatively high-energy process. In fact, the high-energy tail of the internal energy distribution of the ions as a result of the MALDI process combined with high-energy collisions (1-3 collisions) will promote the formation of $\mathrm{d}_{i}$ fragment ions $[25,26]$. Evidence to support this argument can be found in the fragment ion spectrum of Cys-kemptide acquired from low-energy CID performed in a quadrupole ion trap. That is, $[\mathrm{M}-\mathrm{H}]^{-}$ions formed by ESI do not fragment to form d-type fragment ions (Electronic Supplementary Material Figure S1a). Note that $M S^{3}$ fragment ion spectra of the $b_{3}$ and $b_{4}$ fragment ions are provided in the Electronic Supplementary Material (Figures S-1b, S- $1 c$ ). However, the $d_{i}$ fragment ions are not produced through the further activation of ions to form $a_{i}$ ions followed by side-chain elimination resulting in $\mathrm{d}_{i}$ fragment ions. That is, the internal energy of the electrospray-formed $[\mathrm{M}-\mathrm{H}]^{-}$ions is not sufficient to form side-chain cleavage fragment ions; i.e., the internal energy distribution for electrospray-formed ions lacks the highenergy tail that is commonly associated with MALDIformed ions [26]. Additionally, the multiple low-energy collisions in the quadrupole ion trap are not sufficient to promote $\mathrm{d}_{i}$ fragment ion formation.

In order to probe whether the cysteic acid position plays a role in d-type fragment ion formation, we chose to investigate several RNase A proteolytic peptides that have the cysteic acid at the N-terminus, the center, and toward the $\mathrm{C}$-terminus of the peptide. Figure 2 contains the negative ion tandem mass spectra of three oxidized RNase A proteolytic peptides: (a) ${ }^{52} \mathrm{C}_{\mathrm{ox}} \mathrm{NQMMK} \mathrm{K}^{57}$, (b) ${ }^{131} \mathrm{HIIVAC}_{\mathrm{ox}} \mathrm{ENGPY}^{141}$, and (c) ${ }^{93} \mathrm{NGQTNC}_{\mathrm{ox}} \mathrm{Y}^{99}$. Note that methionine residues are also oxidized to the sulfone form (oxidized methionine residues are denoted in italics) as a result of the on-target performic acid oxidation method. Several distinct d-type fragment ions $\left(\mathrm{d}_{2}-\mathrm{d}_{5}\right)$ are observed for ${ }^{52} \mathrm{C}_{\mathrm{ox}} \mathrm{NQMMK} \mathrm{K}^{57}$ (Figure 2a) with an N-terminal cysteic acid. Similar d-type fragment ions are observed for ${ }^{52} \mathrm{C}_{\mathrm{ox}} \mathrm{NQ} M M^{56}$, which lacks the C-terminal lysine residue (Electronic Supplementary Material Figure S-2a). Note that d-type fragment ions formed from the side-chain cleavage of the $\mathrm{C}$-terminal amino acid are not observed for either of these N-terminal cysteic-acidcontaining peptides. When the cysteic acid is adjacent to a lysine residue, d-type fragment ions are still formed. For example, $\left[\mathrm{M}-\mathrm{H}+\mathrm{O}_{3}\right]^{-}$ions of ${ }^{66} \mathrm{C}_{\mathrm{ox}} \mathrm{KPVNTF}^{72}$ form abundant $d_{2}, d_{4}$, and $d_{5}$ fragment ions (Electronic Supplementary Material Figure S-2b). The $d_{3}$ ion for ${ }^{66} \mathrm{C}_{\mathrm{ox}} \mathrm{KPVNTF}^{72}$ is absent because cyclic amino acids (proline) do not produce d-type fragment ions for CID [8]. Collectively, the data suggest that peptides containing cysteic acid favor the formation of d-type ions under two conditions: when the cysteic acid (fixed negative charge) is at the $\mathrm{N}$-terminus and the cleaved amino acid side chains possess a cleavable $\beta-\gamma$ carbon-carbon bond.

As the cysteic acid moves toward the center of the peptide, d-type ion formation is possible for the amino acid side chains that have a cleavable $\beta$ - $\gamma$ carbon-carbon bond to the C-terminal side of the cysteic acid. However, the distinct series of d-type fragment ions are not as prominent as they are for the Nterminal cysteic-acid-containing peptides. The negative ion fragmentation of ${ }^{131} \mathrm{HIIVAC}_{\mathrm{ox}}$ EGNPY ${ }^{141}$ yields two d-type fragment ions, $d_{7}$ and $d_{9}$, corresponding to side chain losses of glutamic acid and asparagine, respectively (Figure 2b). As another example, ${ }^{82} \mathrm{AVC}_{\mathrm{ox}} \mathrm{SQK}^{87}$ yields two d-type fragment ions $\left(\mathrm{d}_{4}\right.$ and $\left.\mathrm{d}_{5}\right)$ through partial side-chain losses of serine and glutamine, respectively (Electronic Supplementary Material Figure S-3a). As for ${ }^{118} \mathrm{YPNC}_{\mathrm{ox}} \mathrm{AY}{ }^{123}$, d-type fragment ions are not observed because the alanine side chain lacks a cleavable $\beta$ $\gamma$ carbon-carbon bond, and side-chain cleavage of an aromatic side chain (e.g., tyrosine) is not favorable (Electronic Supplementary Material Figure S-3b) [8]. However, a w-type fragment ion is observed at the $\mathrm{w}_{4}$ position for the partial side-chain loss of asparagine, with the negative charge retained toward the Cterminus of the peptide. The observation of w-type ions is interesting because we suspect that the side-chain fragment ion type will change to $\mathrm{v}$ - or $\mathrm{w}$-type fragment ions as the cysteic acid moves toward the $\mathrm{C}$-terminus.

As the cysteic acid moves closer to the C-terminus, it appears that $\mathrm{v}$ - and w-type fragment ions are being formed. For example, in the negative ion tandem mass spectrum of ${ }^{93} \mathrm{NGQTNC}_{\text {ox }} \mathrm{Y}^{99}$, two w-type fragment ions ( $\mathrm{w}_{3}$ and $\mathrm{w}_{5}$ ) are observed, corresponding to side-chain losses of asparagine and glutamine, respectively (Figure 2c). Additionally, a low-abundance $\mathrm{v}_{4}$ fragment ion is observed at $\mathrm{m} / z$ 500.37, which corresponds to backbone cleavage at the $\mathrm{y}_{4}$ position with complete side-chain cleavage of the threonine residue. Also note the y-type fragment ions that form as a result of the C-terminal negative charge retention. Similar results 

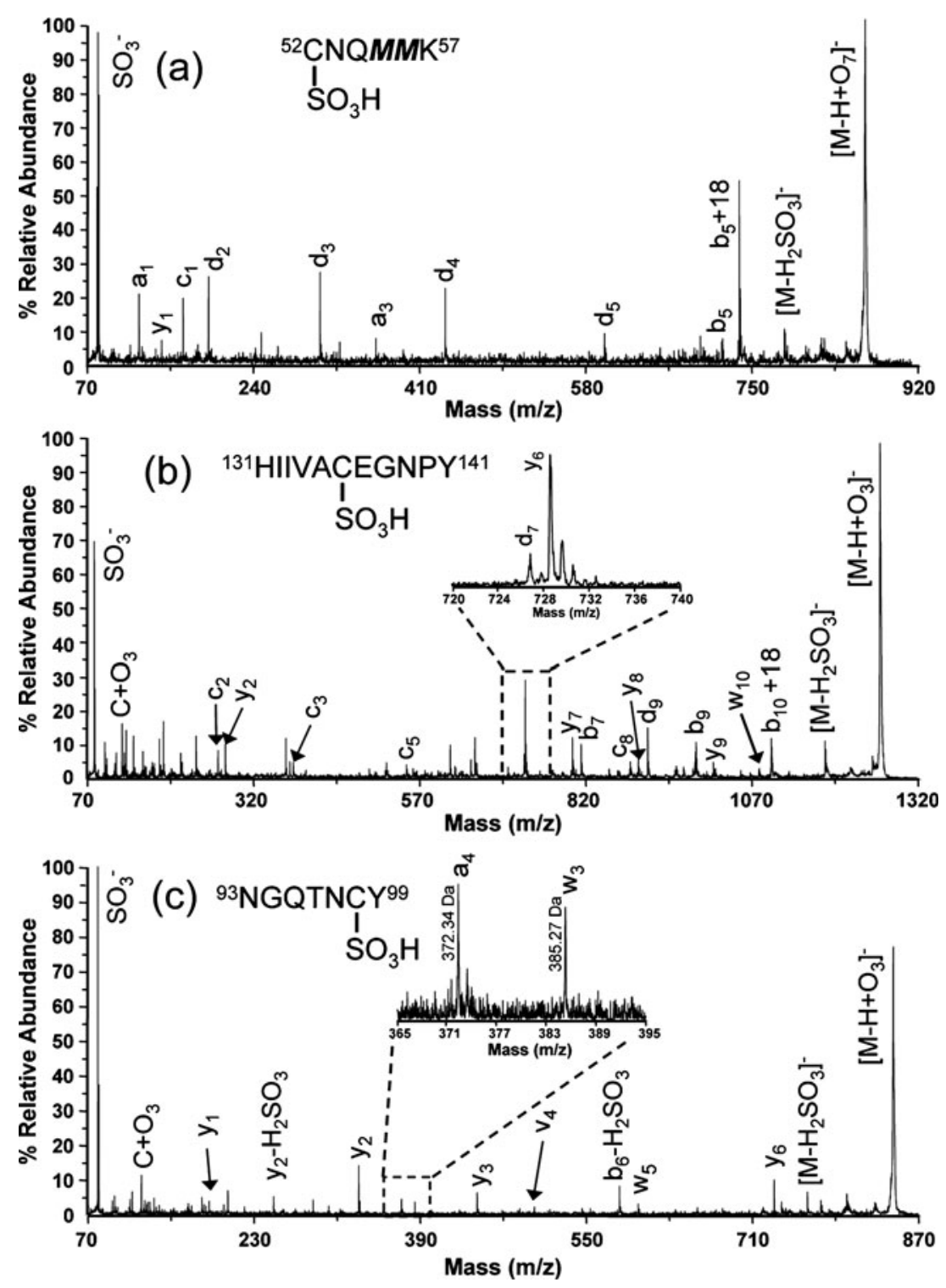

Figure 2. Negative ion tandem mass spectra for oxidized RNase A proteolytic peptides with the cysteic acid at various positions: (a) ${ }^{52} \mathrm{C}_{\mathrm{ox}} \mathrm{NQMMK}^{57}$, (b) ${ }^{131} \mathrm{HIIVAC}_{\mathrm{ox}} \mathrm{EGNPY}^{141}$, and (c) ${ }^{93} \mathrm{NGQTNC}_{\mathrm{ox}} \mathrm{Y}^{99}$. Inset figures: (b) expanded view of mass range $m / z$ 720-740, illustrating that two fragment ions $d_{7}$ and $y_{6}$ are present; (c) expanded view of mass range $m / z$ 365-395, illustrating that two fragment ions $a_{4}$ and $w_{3}$ are present

occur for ${ }^{88} \mathrm{NVAC}_{\mathrm{ox}} \mathrm{K}^{92}$, which produces primarily y-type fragment ions $\left(\mathrm{y}_{1}, \mathrm{y}_{2}\right.$, and $\left.\mathrm{y}_{3}\right)$, with the negative charge maintained toward the C-terminus (Electronic Supplementary Material Figure S-4a). Comparable results are observed in the fragment ion spectrum of ${ }^{106} \operatorname{SITDC}_{\mathrm{ox}} \mathrm{R}^{111}[\mathrm{M}-\mathrm{H}]^{-}$, which primarily forms y-type fragment ions $\left(\mathrm{y}_{2}\right.$ and $\left.\mathrm{y}_{3}\right)$ (Electronic Supplementary Material Figure S-4b). Note that the enhanced ion signal observed for the $\mathrm{y}_{2}$ fragment ion, corresponding to cleavage between the cysteic acid and aspartic acid residues, is similar to previously reported fragmentation processes [27-29].

The generally accepted mechanism for the positive ion formation of $\mathrm{d}_{i}$ ions involves a two-step process in which the first step yields an $\left[a_{i}+1\right]^{+}$ion, followed by side chain $\left(\mathrm{R}_{2}{ }^{\circ}\right)$ elimination (see Scheme 1). The formation of $d_{i}$ ions from $[\mathrm{M}-\mathrm{H}]^{-}$ions from cysteic-acid-containing peptides can be rationalized in a similar manner (see Scheme 2). This proposed mechanism raises a question: why the cysteic acid position dependence? Because the cysteic acid is located at the $\mathrm{N}$-terminus sequestering the charge, the only possibility is to form N-terminal fragment ions. However, when the cysteic acid is located at different locations along the peptide backbone, a mixed population of fragment ions occur; i.e., y-type fragment ions are primarily formed when the cysteic acid is toward the peptide center (y-type fragment ions contain intact $\mathrm{SO}_{3}{ }^{-}$) or near the C-terminus. Note that $\mathrm{d}_{i}$ ions are not observed for N-terminal aspartic- or glutamic-acidcontaining peptides because the negative charge is not 


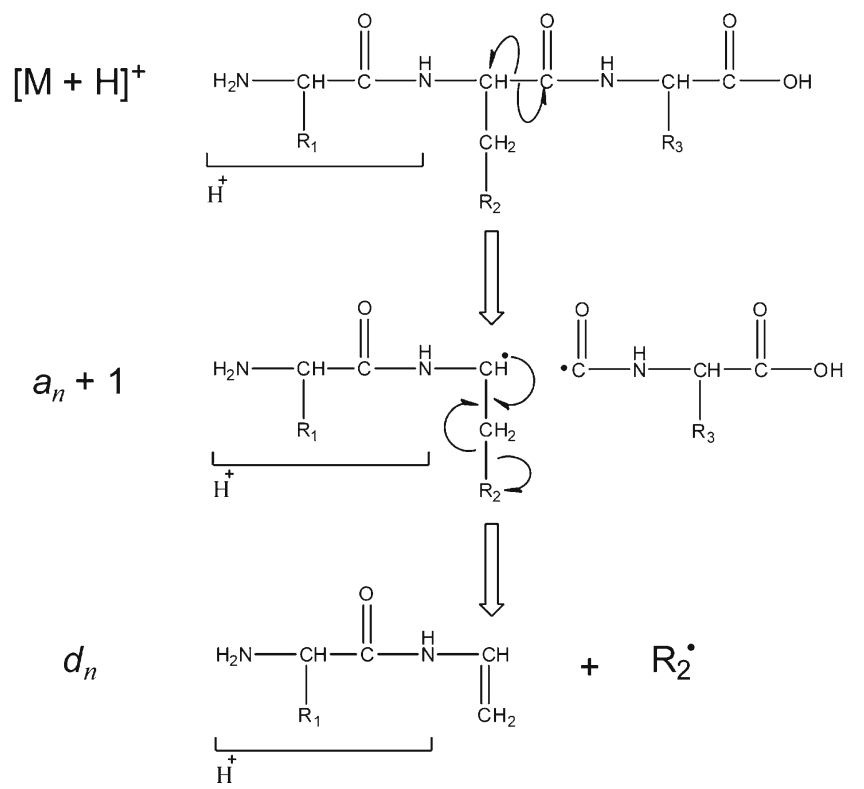

Scheme 1. Positive ion mechanism for the formation of $d_{i}$ ions via the $\left(a_{i}+1\right)^{+}$intermediate with $\mathrm{N}$-terminal positive charge localization

sequestered at the $\mathrm{N}$-terminus (i.e., $\mathrm{SO}_{3}{ }^{-}$is much more stable than any other negative charge carrying site [30]. As an example, the negative fragment ion spectrum for angiotensin II (DRVYIHPFHL) indicates that the negative charge is primarily located at the C-terminus, as there is a near complete series of y-type fragment ions (data not

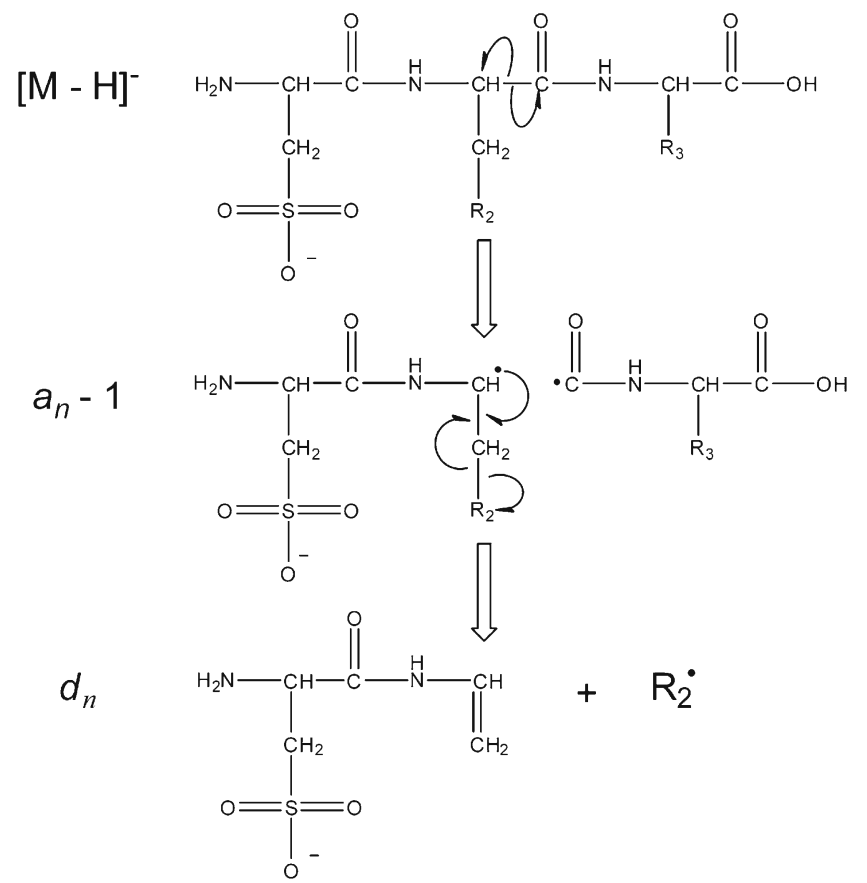

Scheme 2. Negative ion mechanism for the formation of $d_{i}$ ions via the $\left(a_{i}-1\right)^{-}$fragment ion intermediate with an $\mathrm{N}$ terminal cysteic acid shown). The fragmentation reactions leading to $\mathrm{d}_{i}$ fragment ions satisfy the general requirements for charge-remote fragmentation: (i) a stable charge site on either the N- or the $\mathrm{C}$-terminus, (ii) fragment ions all contain the $\mathrm{N}$-terminal cysteic acid, and (iii) the side-chain cleavage reactions occur at elevated collision energies [30, 31]. In fact, the fragmentation reactions along the peptide backbone occur independent of the charge site, indicating that there is no direct interaction between the reaction site and the charge location [31]. In an analogous experiment, fatty acid $[\mathrm{M}-\mathrm{H}]^{-}$ions also fragmented through a charge-remote fragmentation process; i.e., a fixed negative charge site at either end of the molecule and collisional activation are required to achieve extensive decomposition and realize parallel losses of $\mathrm{C}_{n} \mathrm{H}_{2 n+2}$ fragments from the alkyl chain [32]. More recently, a charge-assisted fragmentation mechanism has been reported for $[\mathrm{M}-\mathrm{H}]^{-}$ions of long-chain fatty acids that suggests the involvement of the charge site in the fragmentation reactions (series of $\left[\mathrm{M}-\mathrm{C}_{n} \mathrm{H}_{2 n}+2\right]^{-}$ions) that occur along the fatty acid chain [33]. Therefore, we cannot completely eliminate the involvement of the negative charge site in the $\mathrm{d}_{i}$ fragment ion mechanism. Overall, we assume that the $\mathrm{d}_{i}$ fragment ions resulting from $\mathrm{N}$-terminal cysteic-acid-containing peptide $[\mathrm{M}-\mathrm{H}]^{-}$ions occur through a charge-remote and/or charge-assisted fragmentation mechanism involving consecutive reactions: the formation of $\mathrm{a}_{i}$ ions followed by the elimination of the side chain to form $d_{i}$ ions.

\section{Conclusions}

Near-complete series of d-type fragment ions are observed in the fragment ion spectra for $[\mathrm{M}-\mathrm{H}]^{-}$ions of $\mathrm{N}$ terminal cysteic-acid-containing peptides that possess a cleavable $\beta-\gamma$ carbon-carbon bond on the amino acid side chains $\mathrm{C}$-terminal to the cysteic acid. The cysteic acid acts as a stable negative charge site to enable charge-remote fragmentations to occur under two conditions: (i) the cysteic acid is located at the N-terminus, and (ii) the cysteic-acid-containing peptide $[\mathrm{M}-\mathrm{H}]^{-}$ions are fragmented with CID at relatively high energies (ca. $1 \mathrm{kV}$ ). The types of fragment ions observed depend on the position of the cysteic acid. For example, as the cysteic acid moves toward the center of the peptide, d-type fragment ions are still formed (N-terminal fragment ions), given that the amino acid side chain $\mathrm{C}$-terminal to the cysteic acid contains a cleavable $\beta-\gamma$ carbon-carbon bond. However, when the cysteic acid is near the C-terminus of the peptide, w-type fragment ions are observed (Cterminal fragment ions), but they have a low abundance compared to the distinct d-type fragment ion series. In the near future, we plan to investigate these negative ion fragmentation processes by using model cysteic-acid containing peptides to probe various experimental conditions that could influence the resulting fragment ion types. 


\section{Acknowledgments}

This work was supported by the Department of Energy, Division of Chemical Sciences, Offices of Basic Energy Sciences, BES DE-FG02-04ER15520.

\section{References}

1. Brinkworth, C.S., Dua, S., Bowie, J.H.: Backbone cleavages of $[\mathrm{M}-\mathrm{H}]$ anions of peptides. Cyclisation of citropin 1 peptides involving reactions between the $\mathrm{C}$-terminal $[\mathrm{CONH}]^{-}$residue and backbone amide carbonyl groups. A new type of B cleavage: a joint experimental and theoretical study.Rapid Commun Mass Spectrom 16, 713-721 (2002)

2. Bilusich, D., Bowie, J.H.: Fragmentations of $(\mathrm{M}-\mathrm{H})^{-}$anions of underivatised peptides. Part 2: characteristic cleavages of Ser and Cys and of disulfides and other post-translational modifications, together with some unusual internal processes. Mass Spectrom Rev 28(1), 20-34 (2009)

3. Bowie, J.H., Brinkworth, C.S., Dua, S.: Collision-induced fragmentation of the $(\mathrm{M}-\mathrm{H})^{-}$parent anions of underivatized peptides: an aid to structure determination and some unusual negative ion cleavages. Mass Spectrom Rev 21, 87-107 (2002)

4. Huddleston, M.J., Annan, R.S., Bean, M.F., Carr, S.A.: Selective detection of phosphopeptides in complex mixtures by electrospray liquid chromatography / mass spectrometry. J Am Soc Mass Spectrom 4, 710-717 (1993)

5. Steen, H., Küster, B., Mann, M.: Quadrupole time-of-flight versus triplequadrupole mass spectrometry for the determination of phosphopeptides by precursor ion scanning. J Mass Spectrom 36, 782-790 (2001)

6. Edelson-Averbukh, M., Pipkorn, R., Lehmann, W.D.: Phosphate groupdriven fragmentation of multiply charged phosphopeptide anions. Improved recognition of peptides phosphorylated at serine, threonine, or tyrosine by negative ion electrospray tandem mass spectrometry. Anal Chem 78, 1249-1256 (2006)

7. Borchers, C., Parker, C.E., Deterding, L.J., Tomer, K.B.: Preliminary comparison of precursor scans and liquid chromatography-tandem mass spectrometry on a hybrid quadrupole time-of-flight mass spectrometer. $J$ Chromatogr A 854, 119-130 (1999)

8. Johnson, R.S., Martin, S.A., Biemann, K.: Collision-induced fragmentation of $(\mathrm{M}+\mathrm{H})^{+}$ions of peptides. Side chain specific sequence ions. Int J Mass Spectrom Ion Processes 86, 137-154 (1988)

9. Ellis, H.R., Poole, L.B.: Novel application of 7-chloro-4-nitrobenzo-2oxa-1,3-diazole to identify cysteine sulfenic acid in the AhpC component of alkyl hydroperoxide reductase. Biochemistry36, 1501315018 (1997)

10. Saurin, A.T., Neubert, H., Brennan, J.P., Eaton, P.: Widespread sulfenic acid formation in tissues in response to hydrogen peroxide. Proc Natl Acad Sci USA 101(52), 17982-17987 (2004)

11. Poole, L.B., Karplus, A.P., Claiborne, A.: Protein sulfenic acids in redox signaling. Annu Rev Pharmacol Toxicol 44, 325-347 (2004)

12. Yarnell, A.: Cysteine oxidation. Chem Eng News 87, 38-40 (2009)

13. Dai, J., Wang, J., Zhang, Y., Lu, Z., Yang, B., Li, X., Cai, Y., Qian, X.: Enrichment and identification of cysteine-containing peptides from tryptic digests of performic oxidized proteins by strong cation exchange LC and MALDI-TOF/TOF MS. Anal Chem 77, 7594-7604 (2005)

14. Men, L., Wang, Y.: Fragmentation of the deprotonated ions of peptides containing cysteine, cysteine sulfinic acid, cysteine sulfonic acid, aspartic acid, and glutamic acid. Rapid Commun Mass Spectrom 20, 777-784 (2006)
15. Williams, B.J., Russell, W.K., Russell, D.H.: High-throughput on-target performic acid oxidation method for MALDI deposited samples. J Mass Spectrom 45(2), 157-166 (2010)

16. Summerfield, S.G., Whiting, A., Gaskell, S.J.: Intra-ionic interactions in electrosprayed peptide ions. Int J Mass Spectrom Ion Processes 162, 149-161 (1997)

17. Summerfield, S.G., Cox, K.A., Gaskell, S.J.: The promotion of d-type ions during the low energy collision-induced dissociation of some cysteic acid-containing peptides. J Am Soc Mass Spectrom 8(1), 25-31 (1997)

18. Burlet, O., Yang, C.-Y., Gaskell, S.J.: Influence of cysteine to cysteic acid oxidation on the collision-activated decomposition of protonated peptides: evidence for intraionic interactions. J Am Soc Mass Spectrom 3, 337-344 (1992)

19. Dongré, A.R., Jones, J.L., Somogyi, Á., Wysocki, V.H.: Influence of peptide composition, gas-phase basicity, and chemical modification on fragmentation efficiency: evidence for the mobile proton model. $\mathrm{J} \mathrm{Am}$ Chem Soc 118, 8365-8374 (1996)

20. Edmondson, R.D., Russell, D.H.: Evaluation of matrix-assisted laser desorption ionization-time-of-fiight mass measurement accuracy by using delayed extraction. J Am Soc Mass Spectrom 7, 995-1001 (1996)

21. Xu, H., Zhang, L., Freitas, M.A.: Identification and characterization of disulfide bonds in proteins and peptides from tandem MS data by use of the MassMatrix MS/MS search engine. J Proteome Res 7(1), 138-144 (2008)

22. Roepstorff, P., Fohlman, J.: Proposal for a common nomenclature for sequence ions in mass spectra of peptides. Biol Mass Spectrom 11(11), 601 (1984)

23. Bradford, A.M., Waugh, R.J., Bowie, J.H.: Characterization of underivatized tetrapeptides by negative-ion fast-atom bombardment mass spectrometry. Rapid Commun Mass Spectrom 9, 677-685 (1995)

24. Clipston, N.L., Jai-nhuknan, J., Cassady, C.J.: A comparison of negative and positive ion time-of-flight post-source decay mass spectrometry for peptides containing basic residues. Int $J$ Mass Spectrom 222, 363-381 (2003)

25. Vestal, M.L., Campbell, J.M.: Tandem time flight mass spectrometry. Meth Enzymol 402, 79-108 (2005)

26. Wells, J.M., McLuckey, S.A.: Collision-induced dissociation (CID) of peptides and proteins. Meth Enzymol 402, 148-185 (2005)

27. Yu, W., Vath, J.E., Huberty, M.C., Martin, S.A.: Identification of the facile gas-phase cleavage of the Asp-Pro and Asp-Xxx peptide bonds in matrix-assisted laser desorption time-of-flight mass spectrometry. Anal Chem 65, 3015-3023 (1993)

28. Tsaprailis, G., Nair, H., Somogyi, Á., Wysocki, V.H., Zhong, W., Futrell, J.H., Summerfield, S.G., Gaskell, S.J.: Influence of secondary structure on the fragmentation of protonated peptides. J Am Chem Soc 121, 5142-5154 (1999)

29. Gu, C., Tsaprailis, G., Breci, L.A., Wysocki, V.H.: Selective gas-phase cleavage at the peptide bond $\mathrm{C}$-terminal to aspartic acid in fixed charge derivatives of Asp-containing peptides. Anal Chem 72(23), 5804-5813 (2000)

30. Adams, J.: Charge-remote fragmentations: analytical applications and fundamental studies. Mass Spectrom Rev 9, 141-186 (1990)

31. Cheng, C., Gross, M.L.: Applications and mechanisms of charge-remote fragmentation. Mass Spectrom Rev 19, 398-420 (2000)

32. Jensen, N.J., Tomer, K.B., Gross, M.L.: Gas-phase ion decompositions occurring remote to a charge site. J Am Chem Soc 107, 1863-1868 (1985)

33. Harvey, D.J.: A new charge-associated mechanism to account for the production of fragment ions in the high-energy CID spectra of fatty acids. J Am Soc Mass Spectrom 16, 280-290 (2005) 